\title{
Long Intergenic Non-Protein Coding RNA p53 Induced Transcript
}

National Cancer Institute

\section{Source}

National Cancer Institute. Long Intergenic Non-Protein Coding RNA p53 Induced

Transcript. NCl Thesaurus. Code C118126.

Long intergenic non-protein coding RNA, p53 induced transcript ( $3 \mathrm{~kb})$ is encoded by the human LINC-PINT gene. This non-coding RNA is involved in the regulation of signaling protein gene expression. 